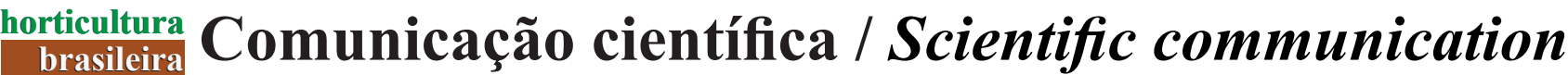

SILVA MS; DIAS MSC; PACHECO DD. 2015. Desempenho produtivo e qualidade de frutos de morangueiros produzidos no norte de Minas Gerais. Horticultura Brasileira 33: 251-256. DOI - http://dx.doi.org/10.1590/S0102-053620150000200018

\section{Desempenho produtivo e qualidade de frutos de morangueiros produzidos no norte de Minas Gerais}

\author{
Márcia S Silva ${ }^{1}$; Mário SC Dias'; ${ }^{1}$ Dilermando D Pacheco ${ }^{2}$ \\ ${ }^{1}$ EPAMIG, Rod. MGT 122, km 155, 39525-000 Nova Porteirinha-MG; masilva.agro@hotmail.com; mariodias@epamig.br; ${ }^{2}$ IF Norte de \\ Minas Gerais, Fazenda São Geraldo s/n, Bom Jardim, 39480-000 Januária-MG; ddpacheco.agro@gmail.com
}

\begin{abstract}
RESUMO
A introdução da cultura do morangueiro no norte de Minas Gerais pode ser uma alternativa viável para a diversificação da produção agrícola local. O clima quente e seco da região pode diminuir a incidência de doenças, aumentando a produtividade e a qualidade dos morangos. O trabalho teve o objetivo de avaliar o desempenho produtivo e a qualidade pós-colheita dos frutos das cultivares de morangueiro Campinas IAC-2712, Sweet Charlie e Dover, cultivados no norte de Minas Gerais. Para determinar o desempenho produtivo foram avaliados o número, a massa fresca média e a produtividade de frutos no campo experimental. O delineamento estatístico utilizado foi de blocos ao acaso com três tratamentos e quatro repetições, sendo as parcelas constituídas de 21 plantas. A qualidade pós-colheita foi determinada em laboratório, avaliando-se o comprimento, diâmetro, firmeza, $\mathrm{pH}$, sólidos solúveis, acidez titulável, açúcares redutores e açúcares totais dos frutos. Adotou-se o delineamento estatístico inteiramente casualizado com três tratamentos, quatro repetições e parcelas de 24 frutos. As análises foram realizadas no início, meio e fim do ciclo da cultura. A cultivar Dover apresentou os maiores índices de produtividade, maior número de frutos e maior massa fresca média destes. Já a Sweet Charlie foi a segunda mais produtiva e a Campinas IAC-2712 apresentou a menor produtividade. As características físico-químicas dos frutos mantiveram-se dentro dos padrões quando comparadas com as dos frutos produzidos em outras regiões. Concluiu-se que as cultivares Dover e Sweet Charlie apresentam potencial produtivo e qualitativo para serem cultivadas no norte de Minas Gerais.
\end{abstract}

Palavras-chave: Fragaria x ananassa, cultivares, clima tropical, produtividade, qualidade pós-colheita.

\begin{abstract}
Productivity and quality of strawberry cultivars in the north of Minas Gerais state

The introduction of strawberry crop in northern Minas Gerais state, Brazil, can be a viable alternative for the diversifying local agricultural production. The hot and dry climate of the region can reduce disease incidence, increasing productivity and quality of strawberries. We evaluated productivity and quality of fruits of the cultivars Campinas IAC-2712, Sweet Charlie and Dover in northern Minas Gerais State, Brazil. To determine performance and productivity, number, average fresh mass and production of fruits were evaluated in a field experiment. The statistical design used was randomized blocks with three treatments and four replications, constituted by portions of 21 plants. The post-harvest quality was evaluated in a laboratory: length, diameter, firmness, $\mathrm{pH}$, soluble solids, acidity, reducing sugars and total sugars of the fruits. The same statistical design was adopted to determine causality using three treatments, four replications and portions of 24 fruits. The analyses were carried out at the beginning, half and end of the crop cycle. The cultivar Dover presented the highest productivity indexes, higher number of fruits and higher average fresh mass. Cultivar Sweet Charlie was the second most productive, and Campinas IAC-2712 presented the lowest productivity. The physicochemical characteristics of the fruits maintained their patterns when compared to fruits produced in other regions. Cultivars Dover and Sweet Charlie presented higher productivity and qualitative potential for cultivation in northern Minas Gerais State.
\end{abstract}

Keyword: Fragaria x ananassa, cultivars, tropical climate, yield, postharvest quality.

(Recebido para publicação em 6 de maio de 2014; aceito em 5 de janeiro de 2015)

(Received on May 6, 2014; accepted on January 5, 2015)

$\mathrm{O}$ morangueiro é cultivado e apreciado nas mais variadas regiões do mundo (Resende et al., 1999). A grande popularidade se deve aos esforços dos melhoristas que, desde o século passado, têm desenvolvido cultivares adaptadas às mais diversas condições ambientais (Hancock et al., 1996).

A produção do morango é quase toda voltada para o mercado doméstico do
Brasil, sendo cerca de $70 \%$ destinada ao consumo in natura e $30 \%$ ao processamento. Em 2006 o país produziu cerca de 100 mil toneladas, cultivadas numa área próxima a 3.500 ha (Antunes \& Réisser Júnior, 2007).

Para Ronque (1998) e Darolt (2002), a escolha de uma cultivar é um dos fatores fundamentais para se obter sucesso no cultivo do morangueiro. Recomenda- -se primeiro uma experimentação local das cultivares disponíveis, evitando assim que se utilizem cultivares inadequadas em regiões de clima adverso. Pelo fato do morangueiro ser muito sensível às variações climáticas, as cultivares têm possibilidade de apresentar características diferentes, dependendo da região em que são plantadas. A cultivar mais bem adaptada a uma região é aquela 
selecionada na própria região, considerando as características de temperatura e fotoperíodo do local de seleção.

No Brasil a cultivar Campinas IAC2712, foi selecionada para consumo in natura na década de cinquenta pelo Instituto Agronômico e ainda hoje é cultivada (Camargo, 1960). É uma planta com boa adaptabilidade a clima ameno e pouco exigente em frio, além de precoce e muito produtiva. $\mathrm{O}$ fruto apresenta boa qualidade organoléptica, entretanto, é de baixa conservação pós-colheita, devido a sua textura. Apresenta alta sensibilidade às principais doenças que acometem o morangueiro (Ronque, 1998).

A cultivar Sweet Charlie foi desenvolvida pela Universidade da Flórida no ano de 1994. É uma cultivar de dia curto, precoce, pouco exigente em frio, produtiva, tolerante à flor preta e bastante cultivada. Produz frutos grandes de excelente qualidade, moderadamente firme e de coloração vermelho-alaranjada externamente e alaranjada internamente (Chandler et al., 2009).

A cultivar Dover foi desenvolvida pela Universidade da Flórida, caracteriza-se como uma cultivar de dia curto, muito produtiva, baixa exigência em frio, maior durabilidade e resistência ao transporte, quando comparada a outras cultivares, demonstrando ser adequada para mercados distantes das áreas de produção. Essa cultivar foi introduzida no Brasil na década de 1990, segundo Howard \& Albregts (1980), para a resistência a antracnose nas condições da Florida.

$\mathrm{O}$ aumento do consumo in natura e principalmente, a maior procura do fruto pelas indústrias de conservas, têm favorecido a expansão da cultura do morangueiro para novas áreas (Lima, 1999). Em vista disso, a caracterização física e química dos frutos é de grande importância quando se estuda o comportamento de cultivares em uma determinada região, pois permite obter informações sobre a qualidade do produto final (Dias et al., 2007).

$\mathrm{O}$ cultivo do morangueiro no norte de Minas Gerais poderá ser uma alternativa viável para a diversificação da produção agrícola. As condições ambientais locais, distintas de áreas tradicionalmente cultivadas com mo- rangueiro, podem diminuir a incidência de doenças e, com isso, as aplicações de defensivos agrícolas, aumentando, assim, a produtividade e qualidade do morango ofertado aos consumidores. Apesar dessa postulação, o morangueiro não tem sido cultivado nessa região do estado, havendo carência total de informação.

Como o comportamento das cultivares de morangueiro é variável, dependendo das variações climáticas regionais, há necessidade de se estudar quais as que melhor se adaptarão ao norte de Minas Gerais. Assim foi proposto o presente trabalho com o objetivo de estudar o comportamento produtivo e avaliar a qualidade dos frutos das cultivares de morangueiro Campinas IAC-2712, Sweet Charlie e Dover.

\section{MATERIAL E MÉTODOS}

O presente trabalho foi realizado na Fazenda Experimental do Gorutuba, pertencente à Empresa de Pesquisa Agropecuária de Minas Gerais, Centro Tecnológico do norte de Minas, município de Nova Porteirinha $\left(15^{\circ} 45^{\prime} \mathrm{S}\right.$; $43^{\circ} 18^{\prime} \mathrm{O}$; $516 \mathrm{~m}$ de altitude).

Foram realizados dois experimentos: o primeiro com o objetivo de estudar o desempenho produtivo de cultivares de morangueiro em condições de campo no norte de Minas Gerais e o segundo para determinar as características físico-químicas dos frutos das cultivares estudadas no primeiro experimento. Foram utilizadas as cultivares Campinas IAC2712, Sweet Charlie e Dover, sendo as mudas obtidas em laboratório de cultura de tecidos.

O solo da área experimental caracteriza-se como Neossolo Quartzarênico (Embrapa, 2006). O terreno foi arado e gradeado, e se preparou os canteiros com as dimensões de 1,0 x 8,4 m. As mudas foram dispostas em três linhas em cada canteiro com espaçamento de $30 \mathrm{~cm}$ entre plantas e entre linhas. De acordo com a interpretação de análise do solo, aplicou-se a cada canteiro 300 L de esterco de curral curtido em 17 de abril de 2002 e, após sete dias foi realizado o transplantio das mudas.
As adubações de cobertura foram iniciadas aos 30 dias após o transplantio das mudas, sendo feitas semanalmente de modo intercalado, ou seja, em uma semana foram fornecidos nutrientes via solo e em outra, via pulverização foliar. O monitoramento dessas adubações foi feito a partir da análise de tecido foliar, que diagnosticou o estado nutricional das plantas.

Os tratos culturais foram os convencionais adotados para a cultura. $\mathrm{O}$ controle químico de doenças não foi realizado, pois não houve manifestação das mesmas. A partir da constatação do ataque de pragas efetuou-se semanalmente a aplicação do inseticida biológico Nim (1 kg de folhas verdes por $10 \mathrm{~L}$ de água) para o controle de ácaros e lagarta rosca, sendo que para esta última utilizou-se também o controle por catação manual.

Os morangueiros iniciaram florescimento em 07 de junho de 2002, sendo a primeira colheita realizada em 25 de junho de 2002 e a última em 11 de novembro de 2002. Os morangos foram colhidos três vezes por semana, quando atingiram 75\% de coloração vermelha. Foram avaliados o número de frutos por planta; massa fresca média dos frutos; produtividade mensal e total de frutos (t/ha).

O delineamento estatístico adotado no primeiro experimento foi de blocos ao acaso com quatro repetições de três tratamentos representados por cada uma das cultivares avaliadas. As parcelas experimentais foram constituídas de vinte e uma plantas, sem bordaduras. Os dados foram submetidos às análises de variância e as médias foram comparadas pelo teste de Tukey ao nível de 5\% de probabilidade.

O segundo experimento foi conduzido em laboratório, com o intuito de analisar a qualidade pós-colheita dos frutos. Foram realizadas três coletas de frutos durante todo o ciclo, isto é, no início (julho/2002), meio (setembro/2002) e final do ciclo (novembro/2002).

Os frutos foram colhidos e selecionados de acordo com a uniformidade de cor, tamanho e ausência de injúrias mecânicas e fisiológicas. Os parâmetros físicos analisados foram comprimento e diâmetro $(\mathrm{cm})$, medidos por meio de paquímetro e resistência da polpa, 
utilizando-se um penetrômetro (marca Ferrari).

A caracterização química constou do $\mathrm{pH}$ \{medido por potenciômetro TECNAL modelo pH Meter TEC-2 (AOAC, 1990)\}; teor de sólidos solúveis (SST) \{determinado em refratômetro digital modelo N-1E (Atago Co., Ltd., Japão), expressando-se os resultados em porcentagem conforme normas da AOAC (1990) (graus Brix)\}; acidez titulável (AT) \{determinada por titulação, expressando-se os resultados em porcentagem de ácido cítrico de acordo com as normas do IAL (1985)\}; açúcares redutores e açúcares totais \{dosados pelo método de Somogy, adaptado por Nelson (1944), sendo os resultados expressos em porcentagem $\}$.

O segundo experimento foi conduzido em delineamento inteiramente casualizado, com três tratamentos, quatro repetições e unidade experimental composta de 24 frutos. Os dados foram submetidos à análise de variância e as médias comparadas pelo Teste de Tukey ao nível de 5\% de probabilidade.

\section{RESULTADOS E DISCUSSÃO}

As cultivares Campinas IAC-2712,
Sweet Charlie e Dover produziram os maiores números de frutos $(19,21,33,72$ e 33,49 , respectivamente) no mês de outubro, seguido do mês de setembro $(10,72,21,03$ e 31,08 , respectivamente para as mesmas cultivares) (Tabela 1). A produtividade da cultivar Campinas IAC-2712, com total de 43,3 frutos/ planta, ficou próxima da encontrada por Calvete et al. (2008), 41,1 frutos/ planta cultivada em ambiente protegido na cidade de Passo Fundo-RS. Castro et al. (2003), em Viçosa-MG, no sistema de cultivo orgânico, obtiveram resultado inferior $(54,9)$ em relação ao encontrado no presente trabalho para a cultivar Dover $(94,0)$.

Comparando os dados obtidos da cultivar Campinas IAC-2712 com os obtidos por Conti et al. (2002) nas regiões de Atibaia-SP $(9,91 \mathrm{~g})$ e Piracicaba-SP $(8,33 \mathrm{~g})$, verifica-se que a média geral da massa fresca média dos frutos produzidos no norte de Minas (6,54 g) são inferiores aos relatados pelos autores. No entanto, esse valor é compatível como uma classificação de primeira que se situa entre 6 a 14 g (Lima, 1999).

A massa fresca média dos frutos da cultivar Sweet Charlie enquadra-se nos valores obtidos por Conti et al. (2002) que estudaram cinco cultivares na região de Piracicaba. Nas três cultivares estudadas, os frutos diminuíram em tamanho e consequentemente perderam peso ao longo do ciclo. O mesmo fato também foi observado por Ronque (1998), que relata que as primeiras flores produzem os maiores frutos, sendo que, em algumas cultivares, a massa fresca média desses frutos foi até duas vezes superior à produzida na florada seguinte. A partir da terceira florada os frutos atingem apenas um terço do tamanho do peso dos primeiros frutos. $\mathrm{O}$ tamanho do fruto também pode estar relacionado ao número de pistilos sobre o receptáculo, pois uma flor inicial pode comportar 500 pistilos, enquanto uma flor final comporta apenas 50 pistilos. Nos meses de junho e julho a cultivar Dover produziu frutos com maior massa fresca média diferindo significativamente de 'Sweet Charlie' e 'Campinas IAC-2712'. Nos meses de setembro, outubro e novembro, a cultivar Dover apresentou comportamento intermediário (Tabela 1).

As maiores produtividades mensais das três cultivares estudadas ocorreram nos meses de setembro e outubro, época de pico de produção no norte de Minas Gerais (Tabela 1). No entanto, Conti et al. (2002) obtiveram diferentes picos de

Tabela 1. Número médio dos frutos por planta, massa fresca média ( $\mathrm{g}$ ) e produtividade média mensal (t/ha) de cultivares de morangueiros \{average number of fruits per plant, average fresh weight and monthly average yield ( $\mathrm{t} / \mathrm{ha}$ ) of strawberry cultivars\}. Nova Porteirinha, EPAMIG, 2002.

\begin{tabular}{|c|c|c|c|c|c|c|c|}
\hline \multirow{2}{*}{ Cultivares } & \multicolumn{7}{|c|}{ Número de frutos } \\
\hline & Jun & Jul & Ag & Set & Out & Nov & Total \\
\hline Campinas IAC-2712 & 0,21 e $\mathrm{A}$ & $5,60 \mathrm{c} \mathrm{B}$ & $5,55 \mathrm{c} \mathrm{B}$ & $10,72 \mathrm{~b} \mathrm{C}$ & 19,21 a B & $2,03 \mathrm{~d} \mathrm{~B}$ & 43,32 \\
\hline Sweet Charlie & 0,14 e $\mathrm{A}$ & $8,92 \mathrm{~cd} \mathrm{~A}$ & $11,61 \mathrm{c} \mathrm{A}$ & $21,03 \mathrm{~b} \mathrm{~B}$ & 33,72 a A & $8,44 \mathrm{~d} \mathrm{~A}$ & 83,86 \\
\hline Dover & 0,09 e A & $5,80 \mathrm{~d} \mathrm{~B}$ & $14,32 \mathrm{~b} \mathrm{~A}$ & 31,08 a A & 33,49 a A & $9,23 \mathrm{c} \mathrm{A}$ & 94,01 \\
\hline \multicolumn{8}{|l|}{ CV (\%) 7,03 } \\
\hline & \multicolumn{7}{|c|}{ Massa fresca média $(\mathrm{g})$} \\
\hline Campinas IAC-2712 & 10,21 a B & $7,04 \mathrm{~b} \mathrm{C}$ & 6,68 bc B & 6,84 bc B & $5,06 \mathrm{~cd} \mathrm{~A}$ & $3,71 \mathrm{~d} \mathrm{~B}$ & 6,59 \\
\hline Sweet Charlie & 10,75 a B & $10,28 \mathrm{ab} \mathrm{B}$ & $7,92 \mathrm{~cd} \mathrm{AB}$ & 8,45 bc A & 6,35 de $\mathrm{A}$ & 5,76 e $\mathrm{A}$ & 8,25 \\
\hline Dover & 16,55 a A & $13,35 \mathrm{~b} \mathrm{~A}$ & $9,43 \mathrm{c} \mathrm{A}$ & $7,80 \mathrm{~cd} \mathrm{AB}$ & 6,30 de $\mathrm{A}$ & 5,62 e A & 9,84 \\
\hline \multicolumn{8}{|l|}{$\mathrm{CV}(\%) 10,75$} \\
\hline & \multicolumn{7}{|c|}{ Produtividade mensal e total (t/ha) } \\
\hline Campinas IAC-2712 & $0,15 \mathrm{~d} \mathrm{~A}$ & $2,95 \mathrm{~b} \mathrm{~B}$ & $2,76 \mathrm{bc} \mathrm{C}$ & 5,50 a $\mathrm{C}$ & 7,29 a B & $0,61 \mathrm{~cd} \mathrm{~B}$ & 19,26 \\
\hline Sweet Charlie & 0,12 e $\mathrm{A}$ & $6,81 \mathrm{c} \mathrm{A}$ & 6,82 c B & $13,22 \mathrm{~b} \mathrm{~B}$ & 15,90 a A & $3,61 \mathrm{~d} A$ & 46,48 \\
\hline Dover & 0,12 e $\mathrm{A}$ & $5,75 \mathrm{~d} \mathrm{~A}$ & $9,98 \mathrm{c} \mathrm{A}$ & 17,97 a A & $15,66 \mathrm{~b} \mathrm{~A}$ & $3,87 \mathrm{~d} \mathrm{~A}$ & 53,35 \\
\hline
\end{tabular}

CV (\%) 15,86

Médias seguidas da mesma letra minúscula nas linhas e maiúscula nas colunas, não diferem entre si pelo teste de Tukey, a 5\% de probabilidade (means followed by same lowercase letters in line and uppercase letters in column are not different, Tukey test, $\mathrm{p}<0.05$ ). 
Tabela 2. Valores médios de comprimento, diâmetro, firmeza, pH, sólidos solúveis, acidez titulável, açúcares redutores e açúcar total de morangos produzidos em três épocas de avaliação \{1 (início), 2 (meio) e 3 (fim do ciclo produtivo)\} \{average values of fruit length, diameter, firmness, $\mathrm{pH}$, soluble solids, titratable acidity, reducing sugars and total sugars in the strawberry prodution in three periods of evaluation, 1 (beginning), 2 (intermediate period) and 3 (end of the crop cycle)\}. Nova Porteirinha, EPAMIG, 2002.

\begin{tabular}{|c|c|c|c|c|}
\hline \multirow{2}{*}{ Análises } & \multirow{2}{*}{ Cultivares } & \multicolumn{3}{|c|}{ Épocas } \\
\hline & & 1 & 2 & 3 \\
\hline \multirow{3}{*}{ Comprimento (cm) } & Campinas IAC-2712 & 3,35 c A & 3,23 b B & $3,13 \mathrm{~b} \mathrm{C}$ \\
\hline & Sweet Charlie & $3,55 \mathrm{~b} \mathrm{~A}$ & $3,25 \mathrm{~b} \mathrm{~B}$ & $3,18 \mathrm{~b} \mathrm{~B}$ \\
\hline & Dover & 4,25 a $A$ & 4,10 a $B$ & 3,65 a $C$ \\
\hline CV $(\%)$ & 1,80 & & & \\
\hline \multirow{3}{*}{$\begin{array}{l}\text { Diâmetro } \\
(\mathrm{cm})\end{array}$} & Campinas IAC-2712 & $2,58 \mathrm{c} \mathrm{A}$ & $2,35 \mathrm{~b} \mathrm{~B}$ & $2,40 \mathrm{c} \mathrm{B}$ \\
\hline & Sweet Charlie & 3,08 a $\mathrm{A}$ & 2,88 a B & 3,15 a $A$ \\
\hline & Dover & $2,90 \mathrm{~b} \mathrm{~A}$ & 2,90 a $\mathrm{A}$ & $2,80 \mathrm{~b} \mathrm{~A}$ \\
\hline $\mathrm{CV}(\%)$ & 2,39 & & & \\
\hline \multirow{3}{*}{$\begin{array}{l}\text { Firmeza } \\
(\mathrm{kgf})\end{array}$} & Campinas IAC-2712 & $0,50 \mathrm{~b} \mathrm{~A}$ & 0,43 с A & $0,25 \mathrm{~b} \mathrm{~B}$ \\
\hline & Sweet Charlie & 1,70 a $\mathrm{A}$ & 1,43 b B & 0,85 a $\mathrm{C}$ \\
\hline & Dover & 1,65 a A & 1,63 a $\mathrm{A}$ & 0,90 a B \\
\hline CV $(\%)$ & 8,00 & & & \\
\hline \multirow{3}{*}{$\mathrm{pH}$} & Campinas IAC-2712 & 3,56 a B & 3,73 a $\mathrm{A}$ & 3,73 a $A$ \\
\hline & Sweet Charlie & 3,65 a B & $3,66 \mathrm{ab} \mathrm{B}$ & 3,82 a $\mathrm{A}$ \\
\hline & Dover & 3,59 a $\mathrm{A}$ & $3,61 \mathrm{~b} \mathrm{~A}$ & $3,42 \mathrm{~b} \mathrm{~B}$ \\
\hline CV $(\%)$ & 1,43 & & & \\
\hline \multirow{3}{*}{$\begin{array}{l}\text { Teor de sólidos } \\
\text { solúveis } \\
\text { (graus Brix) }\end{array}$} & Campinas IAC-2712 & 6,50 a $\mathrm{A}$ & 6,98 a $A$ & 6,48 a $A$ \\
\hline & Sweet Charlie & 6,38 a $\mathrm{AB}$ & 6,63 a $A$ & 5,95 a B \\
\hline & Dover & 6,00 a $\mathrm{A}$ & $5,60 \mathrm{~b} \mathrm{~A}$ & $4,80 \mathrm{~b} \mathrm{~B}$ \\
\hline $\mathrm{CV}(\%)$ & 5,52 & & & \\
\hline \multirow{3}{*}{ Acidez titulável (\%) } & Campinas IAC-2712 & 1,30 a $\mathrm{A}$ & 1,02 b B & $0,85 \mathrm{~b} \mathrm{C}$ \\
\hline & Sweet Charlie & 1,25 a A & 0,92 с B & $0,72 \mathrm{c} \mathrm{C}$ \\
\hline & Dover & 1,30 a $\mathrm{A}$ & $1,15 \mathrm{a} \mathrm{B}$ & 0,98 a C \\
\hline $\mathrm{CV} \%$ & 4,31 & & & \\
\hline \multirow{3}{*}{$\begin{array}{l}\text { Açúcares redutores } \\
(\%)\end{array}$} & Campinas IAC-2712 & 3,12 a C & 4,13 a B & 4,91 a $\mathrm{A}$ \\
\hline & Sweet Charlie & 2,97 a B & 4,10 a $\mathrm{A}$ & $4,28 \mathrm{~b} \mathrm{~A}$ \\
\hline & Dover & 2,78 a A & $3,19 \mathrm{~b} \mathrm{~A}$ & $3,22 \mathrm{c} \mathrm{A}$ \\
\hline CV $(\%)$ & 8,15 & & & \\
\hline \multirow{3}{*}{ Açúcar total (\%) } & Campinas IAC-2712 & 4,71 a $\mathrm{A}$ & 3,87 a B & 3,78 a B \\
\hline & Sweet Charlie & $4,30 \mathrm{ab} \mathrm{A}$ & 3,92 a $\mathrm{A}$ & $2,84 \mathrm{~b} \mathrm{~B}$ \\
\hline & Dover & $3,98 \mathrm{~b} \mathrm{~A}$ & $2,28 \mathrm{~b} \mathrm{~B}$ & $2,62 \mathrm{~b} \mathrm{~B}$ \\
\hline CV $(\%)$ & 10,32 & & & \\
\hline
\end{tabular}

Médias seguidas da mesma letra minúscula nas colunas e maiúscula nas linhas, não diferem entre si pelo teste de Tukey, a 5\% de probabilidade (means followed by the same lowercase letters in column and uppercase letters in line are not different, Tukey's test, $\mathrm{p}<0.05$ ).

produção, nos meses de agosto e setembro. Deve ser considerado que os picos de produção estão relacionados com a época de plantio, ocorrendo geralmente depois de dois meses que a planta começou produzir.

Gusmão et al. (2001) obtiveram al. (2001), produziu 49,91 t/ha, quando cultivada em ambiente natural, e 45,25 t/ ha, sob "não tecido" de polipropileno, na região de Ponta Grossa-PR, produções muito próximas da obtida no presente trabalho (46,48 t/ha).

Marques \& Santi (2009) estudaram o comportamento de cultivares de morangueiro na região de Tangará da Serra-MT e verificaram que a cultivar Dover ( $329 \mathrm{~g} /$ planta) foi mais produtiva do que a Oso Grande (108 g/planta) e Aleluia (25 g/planta). Nas condições do norte de Minas Gerais, também encontrou-se a maior produtividade $(53,35 \mathrm{t} / \mathrm{ha})$ para a cultivar Dover, em relação a Sweet Charlie (46,48 t/ha) e Campinas IAC$2712(19,26 \mathrm{t} / \mathrm{ha})$, mostrando ser uma cultivar altamente produtiva.

A alta produtividade das cultivares Sweet Charlie e Dover na região em estudo pode ser explicada pelos seguintes fatores: ausência de manifestação de doenças; plantio no outono-inverno, sendo que o cultivo se estendeu pela primavera, coincidindo assim com colheita em época de temperatura mais amena (médias no período do experimento entre 18,3 e $31,9^{\circ} \mathrm{C}$, respectivamente para as temperaturas mínimas e máximas) e dias mais curtos; manejo adequado em todo ciclo da cultura; escolha adequada das cultivares e melhor adaptação às condições edafoclimáticas da região.

Os comprimentos dos frutos da cultivar Dover foram de 4,25; 4,10 e $3,65 \mathrm{~cm}$ e para a cultivar Campinas IAC-2712 foram de 3,35; 3,23 e 3,13 cm nas três épocas de avaliação (Tabela 2). Os comprimentos dos frutos da cultivar Sweet Charlie $(3,55 ; 3,25$ e $3,18 \mathrm{~cm})$ no presente trabalho estão próximos ao encontrado por Mosca et al. (2001) quando estudou a mesma cultivar (3,9 $\mathrm{cm})$. Segundo Silva (2007), o tamanho dos morangos pode variar de acordo com a cultivar, o local de plantio e a adubação.

Nas diferentes épocas analisadas, as cultivares apresentaram diferenças significativas quanto ao diâmetro dos frutos. Entretanto, na época 2, as cultivares Dover e Sweet Charlie não apresentaram diferenças significativas. A cultivar Sweet Charlie apresentou diâmetros superiores aos das demais cultivares $(3,08 \mathrm{~cm}$ na época 1 e 3,15 
cm na época 3), como também, diâmetro superior ao encontrado por Mosca et al. (2001), que obtiveram uma média de $2,76 \mathrm{~cm}$ para a mesma cultivar. A cultivar Campinas IAC-2712 foi a que apresentou os menores diâmetros dos frutos e diferiu significativamente das outras cultivares em todas as épocas.

Segundo estudos de Conti et al. (2002), as cultivares Dover e Campinas IAC-2712 apresentaram maior e menor firmeza de frutos, atingindo valores respectivos de 123,27 e 85,75 g, resultados semelhantes aos encontrados no presente trabalho. Os frutos da cultivar Campinas IAC-2712 apresentaram firmeza menor que os frutos da Sweet Charlie e Dover o que caracteriza uma baixa resistência mecânica, podendo demandar maiores cuidados no manejo pós-colheita e limitar o transporte dos mesmos. Nas três cultivares estudadas, na última época de colheita, os frutos apresentaram menor firmeza, provavelmente, devido à coincidência com o período chuvoso, pois o excesso de água e umidade sob os frutos torna-os amolecidos e sujeitos a doença na pós-colheita.

Os valores de $\mathrm{pH}$ obtidos no presente trabalho nas três épocas de avaliação para a cultivar Campinas IAC-2712, foram de 3,56; 3,73 e 3,73, aproximando-se de 3,77 obtidos por Conti et al. (2002) para a mesma cultivar. Para frutos da Sweet Charlie, os valores de $\mathrm{pH}(3,65 ; 3,66$ e 3,82$)$ obtidos neste trabalho estão próximos dos encontrados por Mosca et al. (2001), com média de 3,6. Nas $1^{\mathrm{a}}$ e $2^{\mathrm{a}}$ épocas de avaliação, os frutos da cultivar Dover atingiram valores de $\mathrm{pH}$ iguais a 3,59 e 3,61, respectivamente. $\mathrm{O}$ mesmo diminuiu na $3^{\mathrm{a}}$ época $(3,42)$, ficando, entretanto, ainda próximo da média de 3,66 encontrada por Conti et al. (2002).

A determinação do $\mathrm{pH}$ dos frutos é importante na definição da finalidade de uso das cultivares. Os frutos ácidos $(\mathrm{pH}$ inferior a 3,5) são destinados ao mercado industrial (Passos, 1982), e os frutos menos ácidos são comercializados para o consumo in natura. A característica de $\mathrm{pH}$ torna mais difícil o desenvolvimento de cultivares de dupla aptidão, já que as exigências para uso industrial e consumo in natura são opostas.
O teor de sólidos solúveis é uma característica de grande interesse em frutos que serão comercializados in natura, pois o mercado consumidor prefere frutos doces. As cultivares Campinas IAC-2712 (6,50; 6,98 e 6,48) e Sweet Charlie $(6,38 ; 6,63$ e 5,95) obtiveram maior grau Brix em todas as avaliações exceto na época 1 , onde as cultivares não diferiram entre si estatisticamente. Nas demais épocas, a cultivar Dover obteve valores menores em graus Brix (5,60 e 4,80 ) respectivamente. Resultado semelhante foi citado no trabalho de Conti et al. (2002), que encontraram valores maiores para a cultivar Campinas IAC$2712\left(8,37^{\circ} \mathrm{Brix}\right)$ quando comparada com a Dover $\left(7,10^{\circ}\right.$ Brix $)$. As médias da cultivar Campinas IAC-2712, não diferiram significativamente na $1^{\mathrm{a}}, 2^{\mathrm{a}}$ e $3^{\mathrm{a}}$ época, porém ficaram abaixo da média de $8,37^{\circ}$ Brix, encontrada pelo mesmo autor.

Os valores de sólidos solúveis encontrados no presente trabalho para os frutos da cultivar Sweet Charlie foram inferiores aos encontrados por Virmond \& Resende (2006), que estudaram a produtividade e o teor de sólidos solúveis totais em frutos de morangueiros sob diferentes ambientes de cultivo e verificaram que dentre as cultivares analisadas, a Sweet Charlie apresentou maiores teores de sólidos solúveis $(7,80)$ cultivada em estufa.

Para a avaliação das cultivares isoladamente em relação à acidez titulável, a Campinas IAC-2712 obteve maior acidez na $1^{\mathrm{a}}$ época $(1,30 \%)$, com redução nas épocas seguintes $(1,02 \mathrm{e}$ $0,85 \%)$. A média encontrada na $1^{\mathrm{a}}$ época foi próxima a $1,35 \%$ obtida por Ferrari et al. (2001). As médias obtidas nas $2^{\mathrm{a}}$ e $3^{\mathrm{a}}$ épocas foram inferiores.

A cultivar Sweet Charlie apresentou maior acidez na $1^{\text {a }}$ época $(1,25 \%)$, ficando abaixo da média de 1,51\%, encontrada por Ferrari et al. (2001). Entretanto, nas épocas seguintes $(0,92$ e $0,72 \%$ ), os valores foram próximos a $0,81 \%$ da média obtida por Mosca et al. (2001). A cultivar Dover apresentou diferença significativa para as três épocas de avaliação (1,30, 1,15 e 0,98\%), sendo esses valores superiores aos encontrados por Resende et al. (2008), com acidez de $0,80 \%$ para a cultivar Dover, quando se verificou a análise sensorial e caracterização química de frutos de morangueiro.

Com relação às três cultivares avaliadas separadamente, os valores de acidez decrescem com o avançar das épocas avaliadas. Isso pode ser devido às condições edafoclimáticas, ou mesmo às características de cada cultivar, que podem comportar-se de maneira diferente dependendo do local de plantio.

Para teores de açúcares redutores, na $1^{\mathrm{a}}$ época não houve diferenças significativas nas três cultivares. Nas $2^{\mathrm{a}}$ e $3^{\mathrm{a}}$ épocas, a Campinas IAC-2712 (4,13 e 4,91\%) e Sweet Charlie (4,10 e $4,28 \%$ ), apresentaram os maiores teores de açúcares redutores. Esses valores superaram os encontrados por Silva (2007) nas cultivares Oso-Grande (3,80\%) e Tudla (3,88\%).

A cultivar Campinas IAC-2712 aumentou significativamente o teor de açúcar ao longo das épocas avaliadas. Os teores de açúcares redutores (4,30\%) para a cultivar Campinas IAC-2712, determinados por Ferrari et al. (2001), estiveram na faixa dos estudados nas condições do presente estudo.

O teor de açúcares redutores na cultivar Sweet Charlie foi menor na $1^{\mathrm{a}}$ época, aumentando nas duas últimas épocas, sem entretanto constatar variações significativas. Ferrari et al. (2001) obtiveram uma média de açúcares redutores de $6,60 \%$ ao analisarem morangos produzidos no interior do Paraná, superando às médias do norte de Minas Gerais. As médias de Dover, ao longo das três avaliações, não diferiram significativamente, sendo inferiores a 5,4\%, média de sete cultivares de morangueiro estudadas por Ferrari et al. (2001).

$\mathrm{Na} 1^{a}$ época, os frutos da cultivar Campinas IAC-2712 apresentaram maior quantidade de açúcares totais, enquanto que na Dover verificou-se os menores valores. $\mathrm{Na} 2^{\mathrm{a}}$ época, a Campinas IAC-2712 e a Sweet Charlie não diferiram significativamente, apresentando as maiores médias. $\mathrm{Na} 3^{\mathrm{a}}$ época, as cultivares Sweet Charlie e a Dover também não diferiram significativamente, sendo as médias de ambas inferior à da Campinas IAC-2712. Esta última apresentou valores médios de 4,71; 3,87 e $3,78 \%$ respectivamente nas $1^{\mathrm{a}}, 2^{\mathrm{a}}$ e $3^{\mathrm{a}}$ épocas. Os morangos da cultivar Sweet 
Charlie, na $1^{\mathrm{a}}$ e $2^{\mathrm{a}}$ época, apresentaram maiores teores, com médias de 4,30 e $3,92 \%$, respectivamente. $\mathrm{Na} 3^{\mathrm{a}}$ época, os teores diminuíram significativamente para 2,84\%. Nas três cultivares estudadas, os teores de açúcares totais diminuíram entre a $2^{\mathrm{a}}$ e a $3^{\mathrm{a}}$ época de avaliação, explicando-se isto provavelmente pelo aumento da temperatura com o passar dos meses, influenciando decisivamente na aceleração do metabolismo da planta, incluindo possível quebra de açúcares, sendo que a frutose é responsável pelo sabor doce do fruto, mediante processo respiratório.

Resumidamente, concluiu-se aptidão da cultivar Sweet Charlie para produzir frutos destinados ao consumo in natura, dado à aspectos como morangos de cor vermelho brilhante, uniformes, firmes, tamanho dentro dos padrões, superfície do fruto pouco rugosa o que facilita a limpeza da terra aderente, bom perfume, sabor adocicado e pouca acidez, características citadas por Ronque (1998) como sendo indispensáveis à boa comercialização. Outro atributo do morango norte mineiro, verificado neste trabalho, é a possibilidade de produção sem a utilização de agrotóxicos, sendo este o seu principal diferencial o que certamente poderá torná-lo mais competitivo.

A cultivar Dover apresentou características adequadas para o consumo industrial, como as relatadas por Ronque (1998) que são: frutos de tamanho médio, coloração vermelha externa e internamente, aquênios pequenos e pouco numerosos, fácil separação do cálice, forma cônica ou arredondada e polpa firme para conservar o formato após o cozimento.

De acordo com os resultados de produtividade e qualidade pós-colheita, o morangueiro apresenta potencial para ser cultivado na região semiárida do norte de Minas Gerais, principalmente a cultivar Dover, que superou a média de vários estados brasileiros, e a cultivar Sweet Charlie, que apresentou uma produtividade dentro da média de produção encontrada na literatura consultada. Com relação aos parâme- tros físico-químicos de comprimento, diâmetro, firmeza, $\mathrm{pH}$, sólidos solúveis totais, acidez total titulável, açúcares redutores e açúcar total, foram pouco variáveis quando comparados aos morangos produzidos em outras regiões, mantendo-se dentro dos padrões para serem comercializados.

\section{REFERÊNCIAS}

ANTUNES LEC; REISSER JÚNIOR C. 2007. Produção de morangos. Jornal da Fruta 191: 22-24.

AOAC - ASSOCIATION OF OFFICIAL ANALYTICAL CHEMISTS. 1990. Official methods of analysis. 15 ed. Washington: AOAC.

CALVETE EO; MARIANI F; WESP CL; NIENOW AA; CASTILHOS T; CECCHETTI D. 2008. Fenologia, produção e teor de antocianinas de cultivares de morangueiro em ambiente protegido. Revista Brasileira de Fruticultura 30: 396-401.

CAMARGO LS. 1960. Novas variedades de morangueiro no Estado de São Paulo. Piracicaba: ESALQ. 48p (Tese doutorado).

CASTRO RL; CASALI VWD; BARRELLA TP; SANTOS RHS; CRUZ CD. 2003. Produtividade de cultivares de morangueiro em sistema de cultivo orgânico. Horticultura Brasileira 21: 227-230

CHANDLER CK; ALBREGTS EE; HOWARD CM; BRECHT JK. 2009. 'Sweet Charlie' Strawberry. Disponível em http://edis.ifas. ufl.edu/HS114 Acessado em 26 de fevereiro de 2010.

CONTI JH; MINAMI K; TAVARES FCA. 2002. Produção e qualidade de frutos de diferentes cultivares de morangueiro em ensaios conduzidos em Atibaia e Piracicaba. Horticultura Brasileira 20:10-17.

DAROLT MR. 2002. Morango: Sistema orgânico apresenta viabilidade técnica econômica e ecológica. Disponível em: www.planetaorganico.com.br/darmorang.htm Acessado em 20 de fevereiro de 2010.

DIAS MSC; JÚNIOR PMR; SILVAMS; SANTOS LO; CANUTO RS.; CASTRO MV; COSTA SM. 2007. Caracterização físico-química de morangos cultivados na região norte de Minas Gerais. In: SIMPÓSIO DE PESQUISA EM CIÊNCIAS AGRÁRIAS NO SEMI ÁRIDO MINEIRO, 1. Anais... Janaúba-MG.

EMBRAPA. 2006. Centro Nacional de Pesquisa de Solos (Rio de Janeiro-RJ) Sistema brasileiro de classificação de solos - Brasília: Embrapa. Produção de informação; Rio de Janeiro: Embrapa. Solos. 306p.

FERRARI RA; OTTO RF; SIMÕES DRS. 2001. Avaliação físico-química e sensorial de sete cultivares de morango. Horticultura Brasileira 19 , suplemento CD-ROM.

GUSMÃO MTA; ARAÚJO JAC; GUSMÃO
SAL; VILELA JÚNIOR LVE. 2001. Avaliação do desenvolvimento do morangueiro em relação às variáveis climáticas, em JaboticabalSP. Horticultura Brasileira 19, suplemento CD-ROM.

HANCOCK JF; SCOTT DH; LAWRENCE FJ. 1996. Strawberries. In: JANICK J.; MOORE $\mathrm{JN}$ (eds). Fruit breeding: vine and small fruits crops. New York: John Willey. p. 419-470.

HOWARD CM; ALBREGTS EE. 1980. Dover Strawberry. HortiScience 15: 540.

INSTITUTO ADOLFO LUTZ. 1985. Métodos fisicos e químicos para análise de alimentos. $3^{\mathrm{a}}$ ed. São Paulo: IAL, v.1, 533p.

LIMA LCO. 1999. Qualidade, colheita e manuseio pós-colheita de frutos de morangueiro. Informe Agropecuário 20: 80-83.

MARQUES EL; SANTI A. 2009. Comportamento de cultivares de morango na região de Tangará da Serra-MT. $2^{a}$ Jornada Científica da Unemat, Disponível em http://www2. unemat.br/prppg/jornada2009/resumos_conic/ Expandido_00270.pdf. Acessado em 20 de fevereiro de 2010.

MOSCAJL; SILVAAS; EHLERT PAD; HDALGO A; LIMA JR; GOTO R. 2001. Avaliação físicoquímica e sensorial de morango, das cultivares Toyonoka e Sweet Charlie. Horticultura Brasileira 19, suplemento CD-ROM.

NELSON NA. 1944. Photometric adaptation of the somogy method for the determination of glucose. Journal of Biological Chemists 153: 375-380.

OTTO RF; REGHIN MY; ALTHAUS H; MORAKAMI RK. 2001. Respostas produtivas de quatro cultivares de morangueiro "frigo" cultivadas sob agrotêxtil e em ambiente natural. Horticultura Brasileira 19, suplemento CDROM.

PASSOS FA. 1982. Caracterização de clones nacionais e introduzidos de morangueiro (Fragaria $\mathrm{x}$ ananassa), visando o uso imediato na horticultura e o melhoramento genético. Piracicaba: ESALQ. 116p (Dissertação mestrado).

RESENDE JTV; CAMARGO LKP; ARGANDOÑA EJS; MARCHESE A; CAMARGO CK. 2008. Sensory analysis and chemical characterization of strawberry fruits. Horticultura Brasileira 26: 371-374.

RESENDE LMA; MASCARENHAS MHT; PAIVA BM. 1999. Panorama da produção e comercialização do morango. Informe Agropecuário 20: 5-19.

RONQUE ERV. 1998. A cultura do morangueiro: Revisão e pratica. Curitiba: EMATER/Paraná. 206p.

SILVA PA. 2007. Qualidade de morangos cultivados na região de Lavras-MG, armazenados em temperatura ambiente. Lavras: UFLA. 71p (Dissertação mestrado).

VIRMOND MFR; RESENDE JTV. 2006. Produtividade e teor de sólidos solúveis totais em frutos de morango sob diferentes ambientes de cultivo. Revista Eletrônica Latu Senso 1: 62-69. Disponível em http://www. unicentro.br/propesp/posGraduacao/revista. asp. Acessado em 20 de fevereiro de 2010. 